\title{
Thoracic stent graft sizing for frozen elephant trunk repair in acute type A dissection
}

\author{
Andras Hoffman, MD, ${ }^{\mathrm{a}}$ Anneke L. M. Damberg, MD, ${ }^{\mathrm{a}}$ Gereon Schälte, MD, ${ }^{\mathrm{b}}$ Andreas H. Mahnken, MD, \\ $\mathrm{PhD},{ }^{\mathrm{c}}$ Ayman Raweh, $\mathrm{MD},{ }^{\mathrm{a}}$ and Rüdiger Autschbach, $\mathrm{MD}, \mathrm{PhD}^{\mathrm{a}}$
}

\begin{abstract}
Objective: Although stenting of the descending aorta simultaneously with proximal aortic repair has become an accepted part of the therapy for acute type A dissection, no general recommendations have been accepted regarding the choice of diameter and length of the stent grafts. The present study explored the safety and effectiveness of sizing the stent graft of the hybrid prosthesis in relation to the total aortic diameter and extending the landing zone to the level of the T10-T12 vertebrae.
\end{abstract}

\begin{abstract}
Methods: The frozen elephant trunk procedure was performed on 32 patients with acute type A aortic dissection. The stent graft size was chosen according to the total aortic diameter measured on contrast-enhanced computed tomography scans. The stent graft was inserted with the distal landing zone at the level of vertebrae T10-T12. All patients underwent computed tomography or magnetic resonance angiography before discharge; 8 patients underwent subsequent endovascular stent extension.
\end{abstract}

Results: The 30-day survival was $100 \%$, with $3.1 \%$ (1/32) overall mortality at $17 \pm 4$ months (range, $1-33$ ) of follow-up. The postoperative complications included pneumonia in 5, pulmonary embolism in 3 , sepsis in 1 , and permanent recurrent laryngeal nerve damage in 1 patient. No ischemic brain or spinal cord injury occurred. During follow-up, no endoleaks or false lumen patency developed.

Conclusions: Sizing the stent graft of the hybrid prosthesis according to the total aortic diameter and choosing a distal landing zone between vertebrae T10 and T12 is safe, with low midterm mortality and morbidity. It allows an extensive repair of the dissected aorta with early definite occlusion of the false lumen and prepares for potential endovascular extension of the graft. (J Thorac Cardiovasc Surg 2013;145:964-9)

Supplemental material is available online.

By combining a prosthesis of the aortic arch with a covered endovascular stent graft that is antegradely introduced into the descending aorta, the frozen elephant trunk technique allows extensive 1-stage repair of thoracic aortic dissection. $^{1}$

Although stenting of the descending aorta simultaneously with proximal aortic repair has become an accepted treatment of acute type A dissection, no general recommendations have been accepted concerning the choice of diameter and length of the stent graft. This decision has therefore been driven by concerns other than concept and evidence.

From the Department of Cardiothoracic and Vascular Surgery, ${ }^{\mathrm{a}}$ Department of Anesthesiology, ${ }^{\mathrm{b}}$ and Department of Diagnostic and Interventional Radiology, ${ }^{\mathrm{c}}$ University Hospital RWTH Aachen, Aachen, Germany.

Disclosures: Authors have nothing to disclose with regard to commercial support.

A.H. and A.L.M.D. contributed equally to this study.

Received for publication Dec 22, 2011; revisions received Feb 16, 2012; accepted for publication March 20, 2012; available ahead of print April 16, 2012.

Address for reprints: Anneke L. M. Damberg, MD, Department of Cardiothoracic and Vascular Surgery, University Hospital RWTH Aachen, Pauwelsstrasse 30, Aachen 52074, Germany (E-mail: anneke.damberg@ rwth-aachen.de).

$0022-5223 / \$ 36.00$

Copyright (C) 2013 by The American Association for Thoracic Surgery doi: $10.1016 /$ j.jtcvs.2012.03.059
The sealing capacity of the stent graft of the hybrid prosthesis is supposed to limit residual patency of the false lumen. This is a factor that favors additional enlargement of the aneurysm and the need for reintervention. ${ }^{1,2}$ Residual type $\mathrm{B}$ dissection has been reported to be the most important risk factor for late morbidity, mortality, and redo surgery after acute type A dissection. ${ }^{1-3}$

However, most case series published on the frozen elephant trunk procedure have reported the occurrence of endoleaks and persistent patency of the false lumen distal to the stent graft. ${ }^{1,4}$ Particularly for type A aortic dissection, it has been advised to match the size of the stent graft to the diameter of the true lumen for fear of distal stent perforation, ${ }^{5}$ thereby allowing the false lumen of the dissected descending aorta to remain patent.

Furthermore, stenting of the descending aorta carries the risk of temporary or permanent spinal cord injury, which has been attributed to several risk factors such as a distal landing zone of the stent graft below the vertebral level of T7. ${ }^{1,6}$

In the present study, we report our midterm results using a concept of sizing the stent graft that was intended to minimize the risk of spinal cord injury and completely obliterate the false lumen. The concept consisted of choosing the stent size according to the total diameter of the aorta, regardless of the diameter of the true lumen, and targeting a distal landing zone at the vertebral T10-T12 level. 


\section{Abbreviations and Acronyms}

$\mathrm{CT}=$ computed tomography

SAs $=$ segmental arteries

TEVAR $=$ thoracic endovascular aortic repair

\section{METHODS}

\section{Patients}

Since November 2009, at our institution, the frozen elephant trunk procedure for replacement of the aortic arch and stenting of the descending aorta has been performed on all patients with acute Stanford type A aortic dissection involving the descending thoracic aorta. From November 2009 to September 2011, at our department, 32 patients underwent the procedure. Concomitant aortic root pathologic features were present in 27 patients, who were treated according to the pathologic findings. The patient group consisted of 26 male and 6 female patients, with a mean age of 58 \pm 9 years (range, 32-77 years). The Penn clinical classification ${ }^{7}$ was A (no ischemia) in 14 patients, B (localized ischemia) in 7 patients, $\mathrm{C}$ (hemodynamic instability) in 4 patients, and $\mathrm{B}$ and $\mathrm{C}$ in 7 patients. The details of the preoperative patient characteristics are listed in Table E1.

For the preoperative diagnosis, 64-row computed tomography (CT) angiography was performed on 30 of 32 patients, allowing for evaluation of the extent of the dissection and of concomitant coronary artery disease. In 2 patients with Penn clinical classification $\mathrm{C}$, the aortic dissection was diagnosed using transthoracic echocardiography alone because the patients' clinical instability did not allow transport to the CT scanner.

The patient or a family member provided informed consent for the procedure in all cases.

\section{Hybrid Prosthesis and Stent Graft Sizing}

For the frozen elephant trunk procedure, the E-Vita open plus hybrid prosthesis (Jotec, Hechingen, Germany) was used.

The E-Vita open plus hybrid prosthesis is composed of a 1-piece circular woven polyester fabric tube. The proximal segment is a nonstented woven polyester graft. The distal part of the covered stent graft consists of a polyester tube supported by self-expandable, magnetic resonance compatible $\mathrm{z}$-shaped nitinol springs. The stent is available in diameters of 24 to $40 \mathrm{~mm}$. The nonstented part has a length of $60 \mathrm{~mm}$, the stented part is available in 130, 150, or $160 \mathrm{~mm}$ lengths. Stents with diameters of 24 to $30 \mathrm{~mm}$ are available combined with a $130-$ or $150-\mathrm{mm}$ stent and stents with diameters of 33 to $40 \mathrm{~mm}$ are available combined with stents 130 or $160 \mathrm{~mm}$ long. 8,9

To determine the stent graft size, the total diameter of the descending aorta at the level of the left atrium was determined from the preoperative CT angiography or echocardiography studies (Figure 1). To determine the vessel diameter on CT angiography, we used curved multiplanar reformations along the vessels' centerline. If the measured aortic diameter was between 2 of the available stent graft sizes, the larger stent was chosen. Thus, in some cases, the stent diameter was up to $3 \mathrm{~mm}$ larger than the measured total aortic diameter.

The length of the stent graft was also determined using preoperative CT angiography. Intraoperatively, the point of reference for the positioning of the proximal end of the stent graft was the cusp of the inner curve of the aortic arch (Figure 2). Therefore, we located this point on the preoperative CT angiography study and chose the longest stent graft that would not go beyond T12 and would not cover the celiac trunk. It should be remembered that the celiac trunk can originate at the level of T12 in some patients, although no such case occurred in the present study. Because the stents are only available in defined diameters and lengths, the vertebral level of the distal landing zone depends on the chosen stent diameter, as well as the height of the patient.

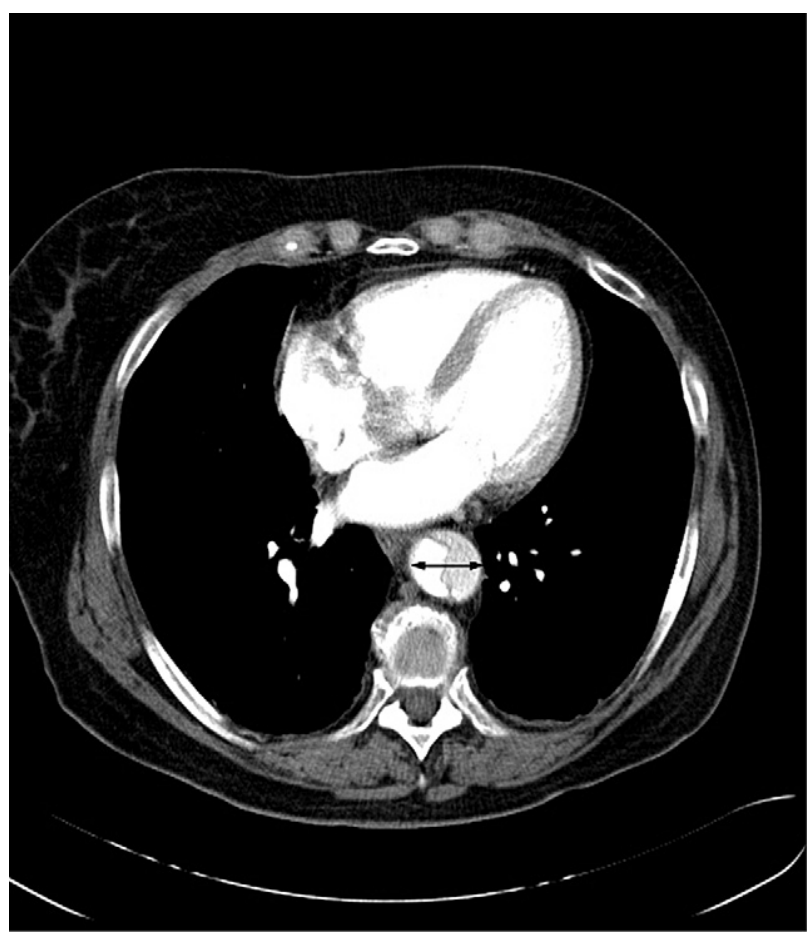

FIGURE 1. Sizing the stent graft diameter. To determine the diameter of the stent graft, the total diameter of the descending aorta (arrow) at the level of the left atrium was measured on the preoperative computed tomography angiography study.

\section{Surgical Sequence}

Preoperatively, all patients were monitored with a central line (left jugular or subclavian), a left radial and femoral arterial line, transcranial Doppler of the medial cerebral artery, and transesophageal echocardiography. All patients received balanced anesthesia using sufentanil, rocuronium, and sevoflurane. We did not use lumbar spinal fluid drainage because in the case of postpunctional bleeding, the surgery cannot be postponed, increasing the risk of more serious perioperative bleeding complications in the spinal canal. ${ }^{10}$

After median sternotomy, extracorporeal circulation and deep hypothermic circulatory arrest were installed for all operations. For aortic cannulation, a subclavian artery (usually on the right) was used. The venous cannula was inserted in the right atrium, except for those patients who had undergone a previous sternotomy. In these cases, a femoral vein was used.

If possible, crossclamping of the aorta was avoided. When a body core temperature of $20^{\circ} \mathrm{C}$ was reached, retrograde crystalloid cardioplegia was instilled, and circulatory arrest was introduced.

The extent of the dissection was evaluated and the aortic arch was resected, leaving the supra-aortic branches connected as an island in most cases. Subsequently, the stent graft of the hybrid prosthesis was introduced into the true lumen of the descending aorta with the distal landing zone at the vertebral T10-T12 level and released. After circumferentially suturing the stent graft to the descending aorta, the woven nonstented part of the graft was extracted and used to replace the aortic arch. In general, the supra-aortic branches were reimplanted into the prosthesis as an island $(n=29)$. A debranching of the supra-aortic vessels was performed only if intraoperative findings showed an entry between the supra-aortic branches $(\mathrm{n}=3)$. In those cases exclusively, antegrade cerebral perfusion was used after anastomosing the branch to a Dacron prosthesis. After retrograde de-airing and repeat crossclamping the prosthesis used for arch replacement, extracorporeal circulation was restarted, and perfusion of the 


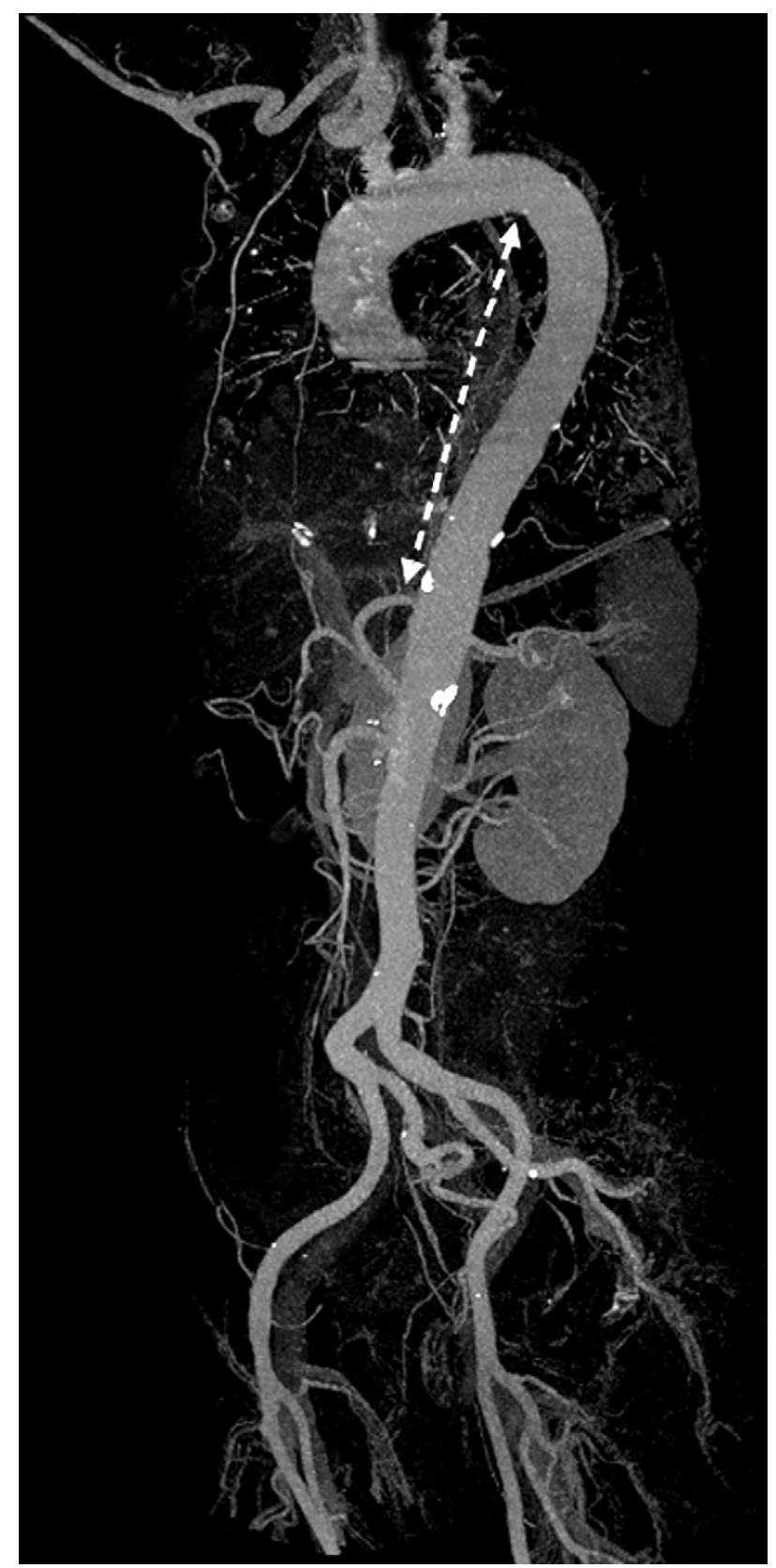

FIGURE 2. Sizing the stent graft length. The point of reference for intraoperative positioning of the stent graft is the cusp of the inner curve of the aortic arch. To determine the maximum length of the stent graft, the distance from this point to vertebra T12 and to the celiac trunk was measured on the preoperative computed tomography angiography study.

brain and distal aorta were evaluated using Doppler monitoring. Subsequently, aortic valve reconstruction $(n=21)$ or the Bentall procedure $(n=6)$ was performed during rewarming, and the ascending aortic prosthesis was finally connected to the arch prosthesis. Detailed intraoperative data are listed in Table 1 .

\section{Follow-up}

Complete follow-up data were available for all patients. The average follow-up period was $17 \pm 4$ months (range, 1-33). Before discharge,
TABLE 1. Operative data $(n=32)$

\begin{tabular}{|c|c|c|}
\hline Variable & $\begin{array}{c}\text { Island } \\
\text { reimplantation } \\
\text { of supra-aortic } \\
\text { vessels }(n=19)\end{array}$ & $\begin{array}{c}\text { Debranching of } \\
\text { supra-aortic } \\
\text { vessels }(n=3)\end{array}$ \\
\hline \multicolumn{3}{|l|}{ Cardiopulmonary bypass time (min) } \\
\hline Mean \pm standard deviation & $204 \pm 40$ & $234 \pm 31$ \\
\hline Range & $116-288$ & $200-261$ \\
\hline \multicolumn{3}{|l|}{ Aortic crossclamp time (min) } \\
\hline Mean \pm standard deviation & $136 \pm 39$ & $167 \pm 36$ \\
\hline Range & $60-215$ & $137-206$ \\
\hline \multicolumn{3}{|c|}{ Deep hypothermic circulatory arrest (min) } \\
\hline Mean \pm standard deviation & $42 \pm 7$ & $72 \pm 3$ \\
\hline Range & $37-64$ & $68-74$ \\
\hline \multicolumn{3}{|c|}{ Selective antegrade cerebral perfusion (min) } \\
\hline Mean \pm standard deviation & & $43 \pm 4$ \\
\hline Range & & $39-46$ \\
\hline \multicolumn{3}{|l|}{ Aortic root procedure $(\mathrm{n})$} \\
\hline Bentall procedure & 6 & \\
\hline Aortic valve reconstruction & 21 & \\
\hline Supracoronary aortic replacement & 5 & \\
\hline Coronary artery bypass graft & 5 & \\
\hline
\end{tabular}

control CT or magnetic resonance angiography was performed in all patients to evaluate the position of the stent, total obliteration of the false lumen, possible endoleaks, and residual dissection. Patients were reevaluated at our outpatient clinic after discharge in 6-month intervals.

\section{Endovascular Extension of Stent Graft}

In 8 patients with persisting type $\mathrm{B}$ dissection distal to the proximal stent, deep thoracic or thoracoabdominal extension of the stent was performed using an endovascular approach (thoracic endovascular aortic repair [TEVAR]; Figure 3). For TEVAR, a self-expandable stent is introduced over a stiff guidewire inserted into the true lumen of the aorta by way of femoral access. The proximal stent of the hybrid prosthesis was used as the landing zone for the distal stent. The stent used for TEVAR is not covered, which allows overstenting of segments carrying important branches, such as the celiac trunk. ${ }^{11}$

TEVAR was considered for patients presenting with complications or persistent symptoms. In asymptomatic patients, we contemplated TEVAR if follow-up imaging showed persistent perfusion of the false lumen distal to the stent graft and a decreasing true lumen area. If TEVAR was indicated, it was performed at least 6 weeks after the patient's initial discharge.

\section{RESULTS}

We performed the frozen elephant trunk procedure using the E-Vita open plus hybrid prosthesis (Jotec) for 32 patients with acute type A dissection. Concomitant aortic root repair was performed in 21 patients; in 6 patients, the aortic root was replaced. Three patients underwent debranching of the supra-aortic vessels.

The postoperative data for the present patient sample are listed in Table E2. The average stent diameter was $30 \pm 3$ $\mathrm{mm}$ (range, $28-36 \mathrm{~mm}$ ) and the distal landing zone varied between the T10 and T12 vertebral levels. Details on the preoperative aortic diameter, diameter and length of the stents used, and distal landing zones are listed in Table 2. 


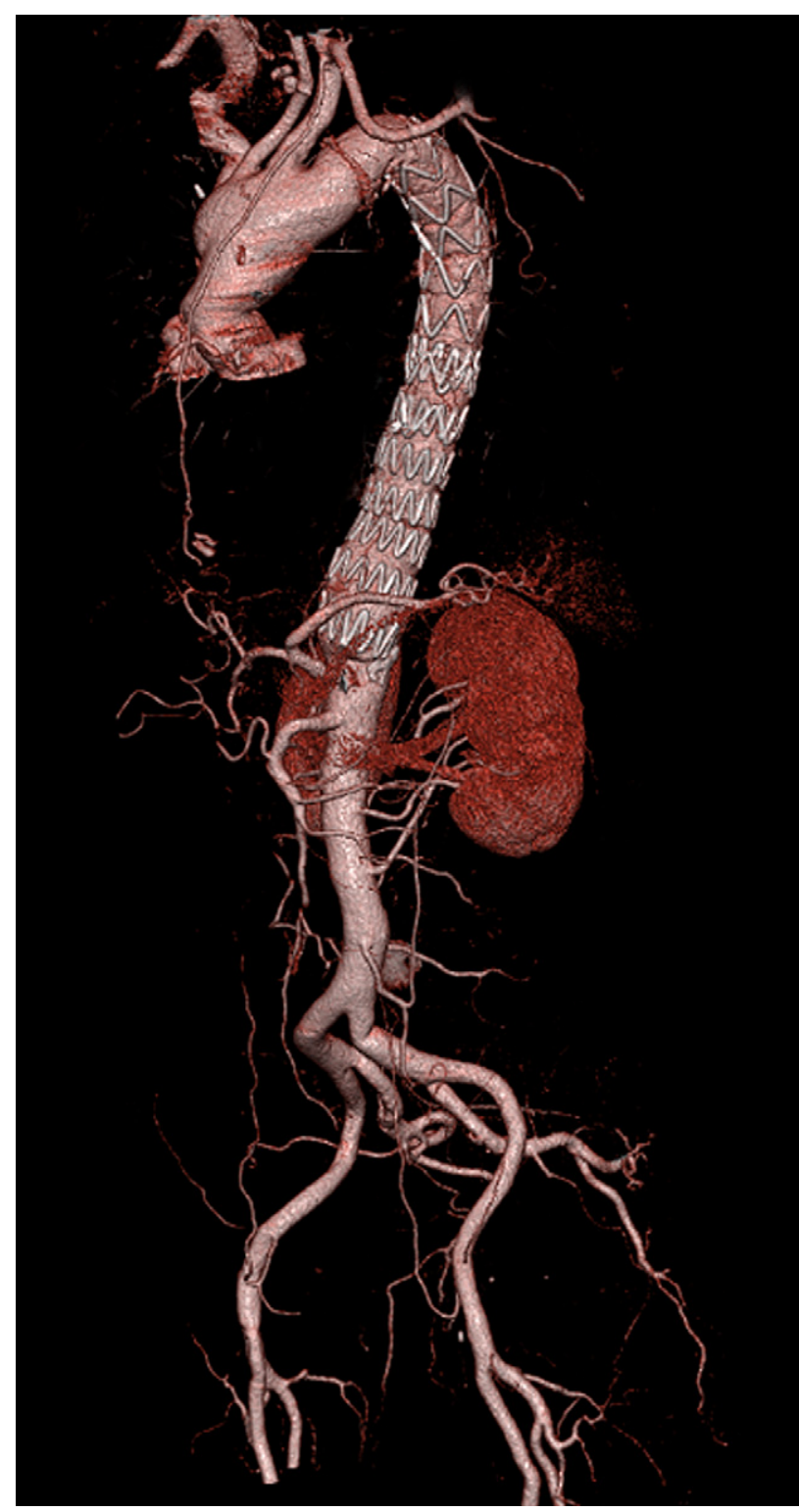

FIGURE 3. Three-dimensional volume-rendered image computed from a postoperative computed tomography angiography study. Frozen elephant trunk procedure combined with second-step endovascular thoracoabdominal extension of the stent. All supra-aortic and visceral arteries were patent.

No patient died in the immediate postoperative period (<30 days). Overall mortality was $3.1 \%$ (1/32). This patient (with Penn classification A) had developed pulmonary sepsis on postoperative day 50 as a result of insufficient mobilization owing to extreme obesity.

The mean length of intensive care unit stay was $12 \pm 6$ days (range, 2-50 days), and the mean length of hospital stay was $19 \pm 8$ days (range, $9-50$ days).

The perioperative complications included pneumonia in 5 patients, pulmonary embolism in 3 , and sepsis in 1 . Of
TABLE 2. Stent graft sizing $(n=32)$

\begin{tabular}{lc} 
Preoperative total aortic diameter $(\mathrm{mm})$ & \\
Mean \pm standard deviation & $29.8 \pm 3$ \\
Range & $25.9-36.2$ \\
Patients (n) & $30 *$ \\
Diameter of stent graft (mm) & \\
$\quad$ Mean \pm standard deviation & $30 \pm 3$ \\
Range & $28-36$ \\
Length of stent graft (n) & \\
150 mm & 24 \\
160 mm & 8 \\
Distal landing zone (n) & \\
T10 & 20 \\
T11 & 8 \\
T12 & 4 \\
\hline
\end{tabular}

*Preoperative total aortic diameter was measured at the level of the left atrium on preoperative computed tomography angiography; in 2 of 32 patients, the diameter was not documented, because it was measured using transesophageal echocardiography only owing to the patients' hemodynamic instability.

the patients with pulmonary embolism, 2 were asymptomatic and 1 required surgical embolectomy.

Four patients required repeat thoracotomy for bleeding. Permanent damage of the recurrent laryngeal nerve was observed in 1 patient, and 6 patients had temporary postoperative delirium.

No cases of new postoperative brain injury or spinal cord ischemia or new distal organ ischemia occurred. One patient with preoperative partial left-hemispheric median infarction and right upper extremity paresis showed CT evidence of an enlarged ischemic area on the fifth postoperative day; however, clinically, no new neurologic deficit appeared.

During follow-up, no endoleaks were detected. At discharge, full obliteration of the false lumen around the stent graft was observed in all cases.

In patients with dissection involving the supra-aortic branches in whom no debranching was performed, an additional entry more distally in 1 of the supra-aortic vessels could possibly result in a patency of the false lumen in the reimplanted island. In the present study, no such case occurred.

In 8 patients, an endovascular thoracic or thoracoabdominal extension of the stent graft was performed. Again, no cases of spinal cord injury were observed.

One patient with a bicuspid aortic valve who had initially undergone aortic reconstruction required aortic valve replacement 2 years postoperatively for aortic regurgitation. Apart from that, no aortic events or redo procedures occurred during follow-up.

\section{DISCUSSION}

During the past decades, modern surgical and perioperative concepts have led to a dramatic reduction of mortality in acute type A aortic dissections. Our current mission is to focus on the long-term morbidity of this disease, which 
is highly dependent on the extension of residual type B dissection. $^{1-3}$

Since November 2009, we chose the stent size for the hybrid prosthesis for the frozen elephant trunk procedure according to the total diameter of the descending aorta with a distal landing zone of vertebrae T10-T12, regardless of the entry site of the dissection.

Our midterm results strengthen the assumption that our concept of a more extensive approach to the thoracic aorta is not associated with increased morbidity and mortality, particularly with regard to the risk of stent perforation ${ }^{5,12}$ and spinal cord injury. ${ }^{1,5,6}$

These complications have discouraged surgeons from choosing longer and larger stents. In contrast, none of these events occurred in our patients.

Our encouraging results indicate the use of larger stents to be feasible and safe with low morbidity and mortality at midterm follow-up. However, the long-term results of this concept remain to be determined.

However, several reasons exist why more extensive stenting of the thoracic aorta in type A dissection seems advantageous. First, choosing the stent size according to the true lumen of the aorta reduces the risk of endoleak and distal perfusion of the false lumen. Both factors favor the persistence and progression of residual type $\mathrm{B}$ dissection. Residual type $\mathrm{B}$ dissection has been reported to be the main risk factor for late morbidity, mortality, and redo intervention. ${ }^{1-3}$

Most studies of the frozen elephant trunk procedure in acute type A dissections using the conventional concept of sizing the stent according to the diameter of the true lumen have reported a significant rate of endoleaks and false lumen patency. The incidence of false lumen patency was reported at 5\% to $23 \% .{ }^{13-15}$ In contrast, Uchida and colleagues $^{16,17}$ and Gorlitzer and colleagues ${ }^{3}$ reported that at mid- to long-term follow-up, thrombosis of the false lumen was observed in all cases. However, it seems that the process of thrombosis and obliteration can be delayed and is unpredictable. Postoperatively, obliteration of the false lumen has been documented to require 3 months to 1 year. ${ }^{3,17}$

Our results at midterm follow-up showed that choosing a stent the size of the total aortic diameter permits immediate closure of the false lumen of the aortic dissection, ensuring obliteration of all intercostal arteries. At hospital discharge, no patient showed signs of endoleak or residual patency of the false lumen.

Karck and colleagues ${ }^{5}$ have refrained from using stents the size of the total aortic diameter because of the risk of aortic wall damage. The only case report of aneurysmal rupture after a frozen elephant trunk procedure was published by Toyama and colleagues ${ }^{12}$; however, the main cause for this complication was kinking of the graft and subsequent endoleak and was not associated with oversizing of the stent. In our series, the membrane of the true lumen showed good elasticity. No stent perforation or complications from aortic wall damage related to the stent occurred. This observation was not surprising because of the usual operative finding that after resection of the arch, the dissection membrane can easily be reapplied to the original aortic wall-a fact cardiac surgeons routinely used in an earlier era to attempt to glue the membranes together.

The second feature of our concept is the choice of a distal landing zone for the stent graft between the T10 and T12 vertebral level.

Most surgeons prefer a higher distal landing zone because of the fear of spinal cord injury, 1 of the most dreaded complications of the frozen elephant trunk procedure. In several case series of the frozen elephant trunk procedure for acute type A dissection, temporary or permanent spinal cord ischemia was reported in $0 \%$ to $24 \%$ of cases. ${ }^{3,6,13-16,18-20}$ Flores and colleagues ${ }^{6}$ stated that the distal landing zone is an independent risk factor for paraplegia and advised against choosing a distal landing zone lower than T7. Uchida and colleagues ${ }^{18}$ reported no stent in patients with acute type A dissection exceeding level T7, and Jakob and colleagues ${ }^{13}$ did not use stent grafts at levels lower than $\mathrm{T} 9$.

Our decision to stent the aorta down to the T10-T12 vertebral level was determined from the findings of Zoli and colleagues $^{21}$ for patients with thoracic aneurysm. They identified the number of segmental arteries sacrificed as the most important risk factor for paraplegia in thoracoabdominal aneurysm repair. They classified 4 risk groups: group A, fewer than 8 segmental arteries (SAs) sacrificed; group B, 8 to 12 SAs with an origin in the upper thorax; group C, 8 to 12 SAs with an origin in the lower thorax; and group D, more than 12 SAs sacrificed. They found that group B was associated with a relatively low paraplegia risk of $3.7 \%$ and groups $\mathrm{C}$ and $\mathrm{D}$ represent comparably high-risk groups with a paraplegia risk of $15.4 \%$ and $12.5 \%$, respectively. ${ }^{21}$

Thus, we concluded that it would be safe to choose T10T12 as the distal landing zone for the stent graft because it would result in occlusion of up to 12 SAs with an origin in the upper thorax (group B). Our results have confirmed this hypothesis. In our series, none of the 32 patients developed temporary or permanent paraplegia.

What we consider crucial for spinal cord protection is optimized perioperative management. As shown by Etz and colleagues $^{22}$ and Acher and Wynn, ${ }^{23}$ intraoperative hypothermia, the administration of steroids and barbiturates, and stable postoperative hemodynamics and sufficient oxygen-carrying capacity seem to be more important for spinal cord protection than the anatomic factors. Our policy is to target a mean arterial pressure greater than $85 \mathrm{~mm}$ $\mathrm{Hg}^{21,24,25}$ and a central venous pressure less than $10 \mathrm{~mm}$ $\mathrm{Hg}^{10,24}$ immediately after the administration of protamine and adjuvant hemostatic therapy for the first 3 days postoperatively. 
Because of postoperative coagulopathy, comprehensive hemostatic therapy is essential to avoid bleeding when targeting greater mean arterial blood pressures.

We have 2 reasons we believe that remodeling the aorta down to the level of vertebrae T10-T12 should be recommended. First, it allows more extensive repair of the dissected aorta and limits the potential for residual type B dissection to a shorter section.

Second, the total occlusion of the segmental arteries down to T10-T12 enhances the redistribution of spinal cord perfusion. The subsequent development of a collateral network allows second-stage endovascular deep thoracic or thoracoabdominal extension of the stent with low paraplegia risk. ${ }^{21,25}$ Choosing a shorter stent for the frozen elephant trunk procedure would cause less collateralization and would therefore result in greater sacrifice of SAs (group C or D) in the second step associated with a greater risk of spinal cord ischemia.

To date, we have performed thoracoabdominal extension of the stent graft using TEVAR in 8 patients without any case of spinal cord ischemia or new distal organ ischemia. These results strengthen our belief that a distal landing zone of T10-T12 for the distal stent graft might be a recommendable preparation for subsequent thoracoabdominal intervention.

However, our study had some limitations. The design of the study was retrospective, and our patient sample was small with relatively short follow-up. Thus, our results might be a statistical coincidence.

Nonetheless, we consider our results promising, and we hope to be able to further improve our management of acute aortic dissection and to report the results from a larger patient sample with long-term results in the future.

\section{CONCLUSIONS}

Our midterm results have confirmed that in the frozen elephant trunk procedure for acute type A dissection, sizing the stent graft according to the total aortic diameter and choosing a distal landing zone at T10-T12 is feasible and safe with regard to stent perforation and spinal cord ischemia. This concept allows more extensive repair of the dissected aorta with definite occlusion of the false lumen, further reducing the well-known late morbidity and mortality from residual type $\mathrm{B}$ dissection at midterm follow-up. Additionally, we are confident that this approach enhances the redistribution of spinal cord perfusion, which will also decrease the risk of paraplegia with second-step deep thoracic or thoracoabdominal extension of the stent. ${ }^{21,25}$

\section{References}

1. Ius F, Hagl C, Haverich A, Pichlmaier M. Elephant trunk procedure 27 years after Borst: what remains and what is new? Eur J Cardiothorac Surg. 2011;40:1-11.

2. Halstead JC, Meier M, Etz C, Spielvogel D, Bodian C, Wurm M, et al. The fate of the distal aorta after repair of acute type A aortic dissection. J Thorac Cardiovasc Surg. 2007; 133:127-35
3. Gorlitzer M, Weiss G, Meinhart J, Waldenberger F, Thalmann M, Folkmann S, et al. Fate of the false lumen after combined surgical and endovascular repair treating Stanford type A aortic dissections. Ann Thorac Surg. 2010;89:794-9.

4. Murzi M, Tiwari KK, Farneti PA, Glauber M. Might type A acute dissection repair with the addition of a frozen elephant trunk improve long-term survival compared to standard repair? Interact Cardiovasc Thorac Surg. 2010;11:98-102.

5. Karck M, Kamiya H. Progress of the treatment for extended aortic aneurysms: is the frozen elephant trunk technique the next standard in the treatment of complex aortic disease including the arch? Eur J Cardiothorac Surg. 2008;33:1007-13.

6. Flores J, Kunihara T, Shiiya N, Yoshimoto K, Matsuzaki K, Yasuda K. Extensive deployment of the stented elephant trunk is associated with an increased risk of spinal cord injury. J Thorac Cardiovasc Surg. 2006;131:336-42.

7. Olsson C, Hillebrant CG, Liska J, Lockowandt U, Eriksson P, FrancoCereceda A. Mortality in acute type A aortic dissection: validation of the Penn classification. Ann Thorac Surg. 2011;92:1376-82.

8. Hoffman A, Parker JA, Raweh A, Autschbach R. Restoration of the thoracic aorta in type A dissection with hybrid prosthesis. Asian Cardiovasc Thorac Ann. 2011; 19:123-7.

9. Jotec GmbH, Hechingen, Germany. E-Vita Open Plus hybrid prosthesis. Available from: http://www.jotec.net/english/produkt.pml?id=21. Accessed November $13,2011$.

10. Fedorow CA, Moon MC, Mutch WA, Grocott HP. Lumbar cerebrospinal fluid drainage for thoracoabdominal aortic surgery: rationale and practical considerations for management. Anesth Analg. 2010;111:46-58.

11. Akin I, Kische S, Rehders TC, Schneider H, Ince H, Nienaber CA. TEVAR: the solution to all aortic problems? Herz. 2011;36:539-47.

12. Toyama M, Usui A, Yoshikawa M, Ueda Y. Thoracic aneurysm rupture due to graft perforation after endovascular stent-grafting via median sternotomy. Eur J Cardiothorac Surg. 2005;27:162-4.

13. Jakob H, Tsagakis K, Tossios P, Massoudy P, Thielmann M, Buck T, et al. Combining classic surgery with descending stent grafting for acute DeBakey type I dissection. Ann Thorac Surg. 2008;86:95-101.

14. Pochettino A, Brinkman WT, Moeller P, Szeto WY, Moser W, Cornelius K, et al. Antegrade thoracic stent grafting during repair of acute DeBakey I dissection prevents development of thoracoabdominal aortic aneurysms. Ann Thorac Surg. 2009;88:482-90.

15. Sun LZ, Qi RD, Chang Q, Zhu JM, Liu YM, Yu CT, et al. Surgery for acute type A dissection using total arch replacement combined with stented elephant trunk implantation: experience with 107 patients. J Thorac Cardiovasc Surg. 2009;138:1358-62.

16. Uchida N, Katayama A, Tamura K, Sutoh M, Kuraoka M, Ishihara H. Frozen elephant trunk technique and partial remodeling for acute type A aortic dissection. Eur J Cardiothorac Surg. 2011;40:1066-71.

17. Uchida N, Shibamura H, Katayama A, Shimada N, Sutoh M. Total arch replacement with an open stent graft for acute type A aortic dissection: fate of the false lumen. Eur J Cardiothorac Surg. 2009;35:83-8.

18. Uchida N, Katayama A, Tamura K, Sutoh M, Kuraoka M, Murao N, et al. Longterm results of the frozen elephant trunk technique for extended aortic arch disease. Eur J Cardiothorac Surg. 2010;37:1338-45.

19. Sun L, Qi R, Chang Q, Zhu J, Liu Y, Yu C, et al. Surgery for Marfan patients with acute type A dissection using a stented elephant trunk procedure. Ann Thorac Surg. 2008;86:1821-5.

20. Sun L, Qi R, Zhu J, Liu Y, Chang Q, Zheng J. Repair of acute type A dissection our experiences and results. Ann Thorac Surg. 2011;91:1147-52.

21. Zoli S, Roder F, Etz CD, Brenner RM, Bodian CA, Lin HM, et al. Predicting the risk of paraplegia after thoracic and thoracoabdominal aneurysm repair. Ann Thorac Surg. 2010;90:1237-45.

22. Etz CD, Luehr M, Kari FA, Bodian CA, Smego D, Plestis KA, et al. Paraplegia after extensive thoracic and thoracoabdominal aortic aneurysm repair: does critical spinal cord ischemia occur postoperatively? J Thorac Cardiovasc Surg 2008; 135:324-30.

23. Acher CW, Wynn M. A modern theory of paraplegia in the treatment of aneurysms of the thoracoabdominal aorta: an analysis of technique-specific observed/expected ratios for paralysis. J Vasc Surg. 2009;49:1117-24.

24. Etz CD, Luehr M, Kari FA, Bodian CA, Smego D, Plestis KA, Griepp RB. Paraplegia after extensive thoracic and thoracoabdominal aortic aneurysm repair: does critical spinal cord ischemia occur postoperatively? J Thorac Cardiovasc Surg. 2008;135:324-30.

25. Bischoff MS, Scheumann J, Brenner RM, Ladage D, Bodian CA, Kleinman G et al. Staged approach prevents spinal cord injury in hybrid surgicalendovascular thoracoabdominal aortic aneurysm repair: an experimental model. Ann Thorac Surg. 2011;92:138-46. 
TABLE E1. Patient data $(n=32)$

\begin{tabular}{lc}
\hline \multicolumn{1}{c}{ Characteristic } & Value \\
\hline Men (n) & 26 \\
Age (y) & $58 \pm 9$ \\
Mean \pm standard deviation & $32-77$ \\
Range & 14 \\
Age $\geq 60$ y (n) & \\
Preoperative comorbidity (n) & 4 \\
Stroke & 3 \\
Coronary artery disease & 1 \\
Myocardial infarction & 2 \\
Atrial fibrillation & 4 \\
Chronic obstructive pulmonary disease & 1 \\
Chronic kidney disease & 2 \\
Confirmed Marfan syndrome & \\
Penn classification (n) & 14 \\
A & 7 \\
B & 4 \\
C & 7 \\
B+C & \\
Acute malperfusion (n) & \\
Cardiac & 3 \\
Cerebral & \\
Renal & \\
Extremities & 1 \\
\hline
\end{tabular}

TABLE E2. Postoperative data $(n=32)$

\begin{tabular}{|c|c|}
\hline Variable & Value \\
\hline \multicolumn{2}{|l|}{ Mortality (n) } \\
\hline Early $(<30 \mathrm{~d})$ & 0 \\
\hline Late $(>30 \mathrm{~d})$ & 1 \\
\hline \multicolumn{2}{|l|}{ Complications (n) } \\
\hline Repeat thoracotomy for bleeding & 4 \\
\hline New postoperative brain injury & 0 \\
\hline New distal organ ischemia & 0 \\
\hline Spinal cord ischemia & 0 \\
\hline Pneumonia & 5 \\
\hline Pulmonary embolism & 3 \\
\hline Sepsis & 1 \\
\hline Temporary postoperative delirium & 6 \\
\hline Recurrent laryngeal nerve damage & 1 \\
\hline Endoleak (n) & 0 \\
\hline False lumen patency (n) & 0 \\
\hline \multicolumn{2}{|l|}{ Additional operation (n) } \\
\hline Pacemaker implantation & 2 \\
\hline Aortic valve replacement & 1 \\
\hline \multicolumn{2}{|l|}{ ICU stay (d) } \\
\hline Mean \pm standard deviation & $12 \pm 6$ \\
\hline Range & $2-50$ \\
\hline \multicolumn{2}{|l|}{ Hospital stay (d) } \\
\hline Mean \pm standard deviation & $19 \pm 8$ \\
\hline Range & $9-50$ \\
\hline \multicolumn{2}{|l|}{ Follow-up (m) } \\
\hline Mean \pm standard deviation & $17 \pm 4$ \\
\hline Range & $1-33$ \\
\hline
\end{tabular}

